\title{
Did Prices Really Soar after the Euro Cash Changeover? Evidence from ATM Withdrawals*
}

\author{
Paolo Angelini ${ }^{\mathrm{a}}$ and Francesco Lippi ${ }^{\mathrm{b}}$ \\ ${ }^{a}$ Research Department, Bank of Italy \\ ${ }^{\mathrm{b}}$ University of Sassari and CEPR
}

The introduction of the euro notes and coins in the first two months of 2002 was followed by a lively debate on the alleged inflationary effects of the new currency. In Italy, as in the rest of the euro area, survey-based measures signaled a much sharper rise in inflation than that measured by the official price indices, the quality of which was called into question. In this paper we gather indirect evidence on the behavior of prices from the analysis of cash withdrawals from automated teller machine (ATM) terminals. Since these data do not rely on official inflation statistics, they provide an independent check for the latter. We present a simple set of assumptions to test the hypothesis that, after the introduction of the euro notes and coins, consumer prices increased more than was recorded by the official statistics. We do not find evidence in support of this hypothesis.

JEL Codes: E31, E41, E50.

Whatever the experts say, many European consumers still feel retailers are masking price increases with the changeover to the euro.

(Wall Street Journal Europe, January 28, 2002)

${ }^{*}$ This paper was initially drafted while Francesco Lippi was working at the Bank of Italy. We are indebted to Guerino Ardizzi, Paolo Del Giovane, Eugenio Gaiotti, and Roberto Sabbatini for comments on an earlier draft. All remaining errors are our own. Author contact: Angelini: Research Department, Bank of Italy, Via Nazionale 91, 00184, Rome, Italy. E-mail: paolo.angelini@ bancaditalia.it. 
Two out of three eurozone consumers felt they were ripped off by retailers during the changeover to pricing in euros, according to the European Commission.... Germany, France and Netherlands were the countries with the highest percentage of people feeling cheated.

(Financial Times, March 1, 2002)

German consumers dubbed the currency the Teuro (teuer is German for expensive).... Some consumers believe higher prices were the result of retailers rounding up prices as they switched out of their old national currencies into the euro. However, EU statisticians insisted prices had not been affected.

(Financial Times, December 12, 2002)

\section{Introduction}

There is a widespread perception among the citizens of the euro area that the introduction of the euro notes and coins in the first months of 2002 spurred a rise in prices that was much sharper than that measured by the national statistical offices (see European Central Bank 2002b, 2003a, 2003b). This phenomenon, illustrated in figure 1, has been the subject of countless newspaper articles and several official speeches by policymakers and politicians. While the quotations reported above refer to 2002, the perception that the euro brought about price increases is still vivid. ${ }^{1}$

It is somewhat puzzling that a change in the unit of account might have an impact on inflation. Indeed, a number of conjectures have been formulated to explain the discrepancy between inflation perceptions and the official statistics, emphasizing the role of psychological factors (see, e.g., Traut-Mattausch et al. 2004) and/or

\footnotetext{
${ }^{1}$ In May 2002 Professor Otmar Issing gave a speech in Mainz titled "The Euro-A Stable Currency for Europe." After the speech, the first question from the audience was about the "teuro" phenomenon. Seeing the look of disbelief with which his explanation was met, Issing replied, "You seem not to believe me. And even my wife doesn't believe me." This statement found wide coverage in the German press. Two years later, President Trichet still deemed it necessary to reassure European customers on this issue: "European citizens who still perceive that inflation is higher than measured by official indices should be assured that the official measures are accurate and that we will continue to maintain price stability in the future" (introductory statement after the European Central Bank's Governing Council meeting of April 2004).
} 
Vol. 3 No. 4 Did Prices Really Soar after the Euro Cash Changeover? 3

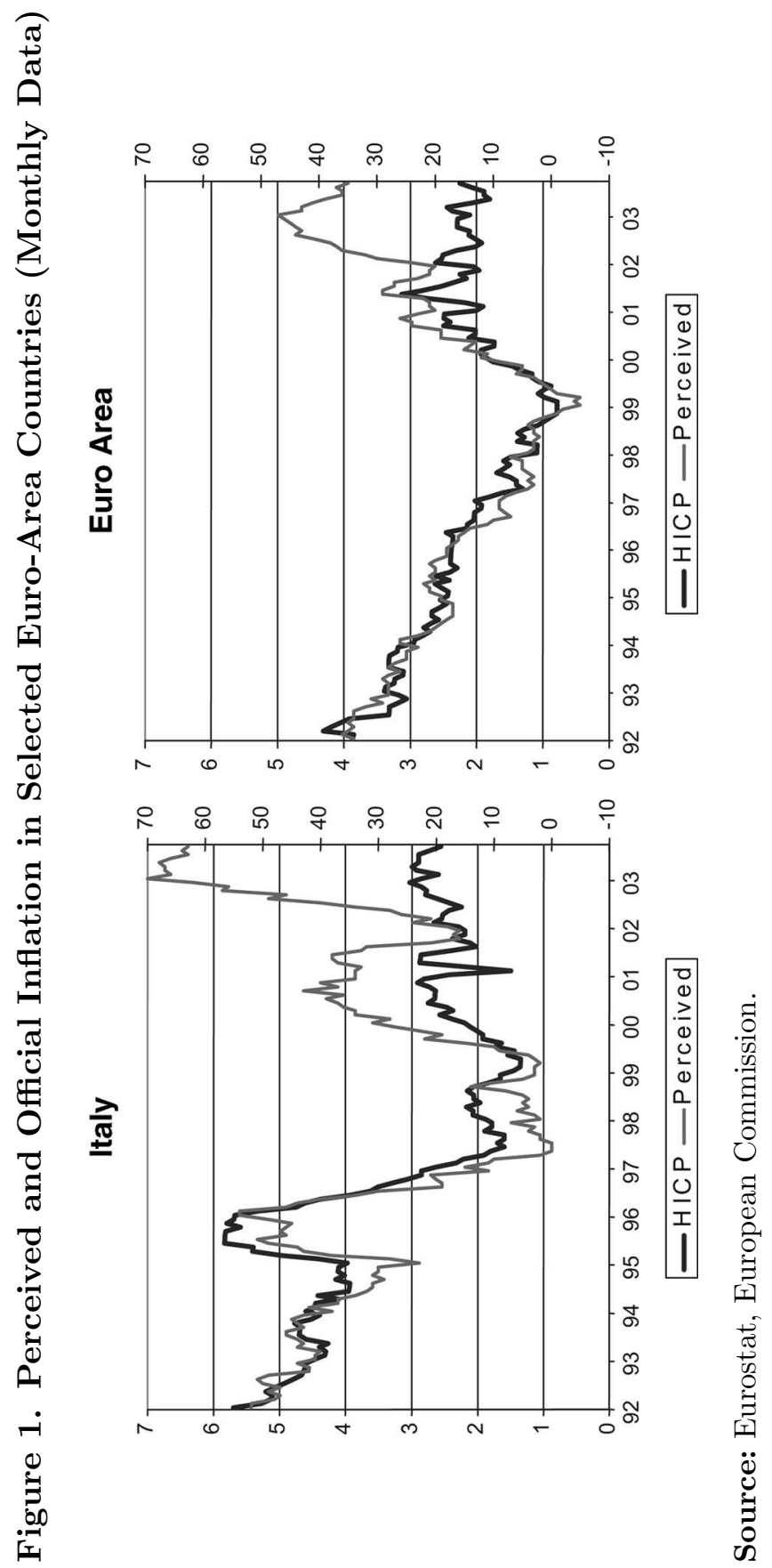

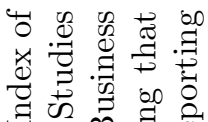

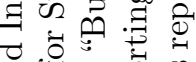

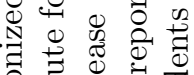
离 $\prod_{i=1}^{\infty}$,

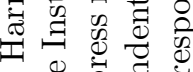
o 8 †

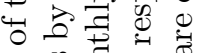

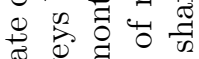

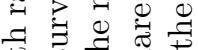

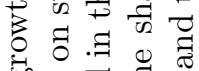
50웜요 㓤 击

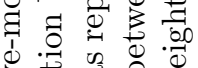
1. 范

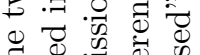
‡. >

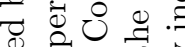

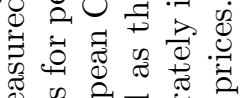

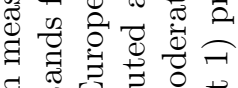

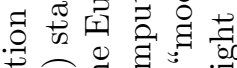

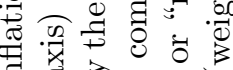

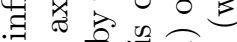

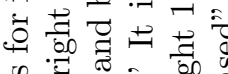
记 $=\frac{.00}{0}$

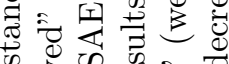
के 20 क

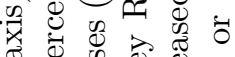
०

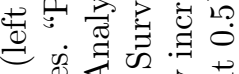
$=$. $\hat{H} .0000$

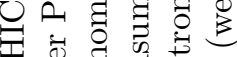
प्र

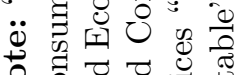

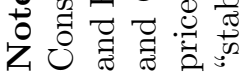


the disproportionate influence of a few industry prices on individual perceptions. Gaiotti and Lippi (2004) and Hobijn, Ravenna, and Tambalotti (2006) analyze the dynamics of restaurant prices and find evidence consistent with a price hike (mainly driven by a lumping of price revisions in an industry where price revisions are normally infrequent). Deutsche Bundesbank (2004) provides comparable evidence for some German services (restaurants, cinemas, dry cleaners, and hairdressers). Other papers argue that inflation perceptions are mainly affected by the prices of goods that are cheaper and more frequently purchased (Del Giovane and Sabbatini 2005; Ehrmann 2005). Dziuda and Mastrobuoni (2005) and Mastrobuoni (2004) present a model that rationalizes why such goods are the ones that actually record greater price increases. While useful, these studies do not provide a direct answer to whether the general price level was measured with error during the changeover. Rather, they maintain the assumption that official statistics are correct. The main obstacle faced by researchers interested in verifying that assumption is the absence of reliable alternative inflation measures. The thesis that price increases were much larger than the increase measured by the national statistical offices, suggested by the indicators of perceived inflation, remains mostly based on anecdotal evidence.

This paper investigates the dynamics of the general price level in Italy after the introduction of the euro notes and coins (the so-called cash changeover), at the beginning of January 2002, by using data on currency withdrawn from the automated teller machine (ATM) network. We believe that this inference is useful because it relies on data collected and assembled by central banks, with methodologies that are completely independent of those used by the national statistical offices to measure prices. The basic steps of our investigation can be summarized as follows. We set up a simple model of ATM withdrawals and estimate it prior to the changeover, when official statistics were arguably correct. We then present a set of assumptions under which the estimated demand equation for ATM withdrawals can be used to back out price-level dynamics from the observed nominal time series for ATM withdrawals and consumer expenditures. Specifically, we show that if a bias materialized in the official data on prices after the changeover, but not in those on cash withdrawals and consumption expenditures, then extending the estimation sample to the changeover period (2002-03) should cause a 
specific form of instability in the estimated coefficients, which can be captured econometrically. Formally, we test the null hypothesis that the increase in consumer prices is correctly measured by official statistics after the changeover. Both a price-level-bias and an inflationbias hypothesis are formulated and tested. The analysis fails to find evidence consistent with the occurrence of a price hike after the changeover. This result cannot be attributed to lack of power of the test: a counterfactual exercise suggests that our methodology is sufficiently powerful to identify an inflation bias greater than 0.5 percentage point.

Several reasons motivate our focus on Italy. First, the country is broadly representative of the euro area in terms of the discrepancy between official and perceived inflation (figure 1). Also, quarterly data on cash withdrawals are available, whereas comparable data are available only at an annual frequency for other euro-area countries (to our knowledge). It is important to explain why we focus on the flow of currency withdrawn from the ATM circuit rather than on more traditional monetary aggregates. The stock of currency experienced a strong decline from the beginning of 2001 (apparently reflecting weak demand of bank notes as a store of wealth due to the approaching currency changeover) and an equally strong rebound thereafter. ${ }^{2}$ Among the traditional monetary aggregates, M1 is strongly affected by the erratic behavior of currency. M2 and M3 are comparatively less affected, but they are typically less related to transactions; in addition, over the recent past, the dynamics of these aggregates has been influenced by portfolio reasons, as repeatedly stressed by the European Central Bank. By contrast, there is no obvious reason why ATM withdrawals - mainly driven by transactions demand - should have been affected by these same factors. The data in figure 2 (shown in section 3) broadly confirm this view: neither the average number nor the unit value of ATM withdrawals made in each quarter by a typical cardholder shows the discontinuity that clearly

\footnotetext{
${ }^{2}$ See, e.g., European Central Bank (2002a). As we argue in what follows, this decline is likely due to the attempt by currency holders to run down their cash inventories. These are mainly held in large-denomination notes and are to a significant (although not easily quantifiable) extent held outside the national borders and/or for gray/black economy purposes.
} 
stands out for the traditional monetary aggregates around the changeover.

The paper is organized as follows. The next section presents a simple model of the demand for ATM withdrawals, which is used as a guideline in the empirical analysis of section 3. Section 4 concludes.

\section{A Simple Model of Aggregate ATM Withdrawals}

This section presents a model aimed at interpreting the evolution of aggregate ATM withdrawals. To match the aggregate data, we first focus on the choice concerning the withdrawals by a representative ATM cardholder and, next, present an aggregation to account for the growing number of cardholders over our estimation period. $^{3}$

Let $i$ index an agent who possesses an ATM card and $E^{i}$ denote that agent's nominal consumption expenditure over a given time span. To pay for $E^{i}$, the agent can use cash $C^{i}$ withdrawn from an ATM, bearing a cost $r^{c}$, or some other means of payment $Q$ (e.g., point of sale [POS], credit card, or checks), the cost of which is denoted by $r^{q}$. The demand schedule for the agent's ATM withdrawals is of the following form: $C^{i}=\Phi\left(r^{q} / r^{c}\right) E^{i}$, where the function $\Phi(\cdot)$ is increasing and concave. ${ }^{4}$ This demand function stipulates that the proportion of cash withdrawals over total nominal expenditure is decreasing in the relative cost between ATM cash and that of alternative means of payments.

To give empirical content to these costs, in the analysis that follows we assume that the cost of ATM cash, $r^{c}$, is increasing in the nominal interest rate $R$ (the value of which determines the amount of forgone interest on deposits) and decreasing in the size of the ATM network, $d^{A T M}$. Moreover, we proxy the cost of alternative payment means, $r^{q}$, using a measure of development of the POS network,

\footnotetext{
${ }^{3}$ Based on the Survey of Households' Income and Wealth conducted by the Bank of Italy, between 1989 and 2004 the proportion of households owning an ATM card rose from 15 percent to 66 percent.

${ }^{4}$ This cash/credit choice can be thought of along the lines of Lucas and Stockey (1987).
} 
denoted by $d^{Q} .{ }^{5}$ The individual proportion of cash expenditures is thus hypothesized to depend on the diffusion of the ATM and POS network and the nominal interest rate:

$$
C^{i}=\Phi\left(d^{Q} / r^{c}\left(d^{A T M}, R\right)\right) E^{i} .
$$

Let us now consider the aggregation problem. In order to bring equation (1) to the data, we need to relate the nationwide demand for ATM cash to aggregate consumption, as data on total expenditure of ATM cardholders are not available. Let $n$ and $\bar{E} / P$ denote the number of ATM cardholders and their aggregate expenditure (deflated by the price level), respectively. Analogously, let $N$ and $E / P$ denote the population size and real aggregate expenditures. We postulate the following:

$$
\bar{E} / P=(n / N)(E / P)^{\delta} .
$$

This equation states that the growth in the aggregate expenditure of cardholders is proportional to the growth of the population fraction of cardholders and to the growth rate of aggregate expenditures, with a constant of proportionality that may differ from 1 .

Aggregating equation (1) over all cardholders and replacing $\bar{E}$ using (2) yields an expression relating the real aggregate flow of ATM withdrawals to real aggregate expenditure:

$$
C / P=(n / N) \Phi\left(d^{Q} / r^{c}\left(d^{A T M}, R\right)\right)(E / P)^{\delta} .
$$

Equation (3) summarizes the determinants of aggregate ATM cash withdrawals discussed thus far. $C$ is increasing in ATM diffusion $\left(d^{A T M}\right)$ and decreasing in the nominal interest rate $(R)$ and in the ease of resorting to noncash payments $\left(d^{Q}\right)$. The elasticity of aggregate cash withdrawals with respect to aggregate expenditure is given by $\delta$. It is immediate that if $\delta$ is equal to 1 , then the price level drops from equation (3) and no information about it can be retrieved from that equation. For all other values, instead, one can invert equation (3) and use the information on $C$ and $E$ to back out

\footnotetext{
${ }^{5}$ In Italy, our data source for the tests presented in the next section, it is not possible to get cash back at POS. This option, available to customers in several industrialized countries, would have made this proxy questionable.
} 
the price level. In section 3.2 we discuss the functional form adopted in equation (2) and review the available empirical evidence on $\delta$, which is key for our identification of price-level dynamics.

\section{Empirical Evidence}

This section begins by presenting some descriptive evidence on ATM withdrawals during the period 1993-2003. Using equation (3) as a guide for the empirical specification, we estimate a currencyexpenditure equation and formally test for the presence of measurement error in the aggregate price level. We conclude the section by exploring the power of the statistical test and analyzing the robustness of the estimates (considering, e.g., parameter instability and potential endogeneity of the regressors).

\subsection{A Preliminary Look at the Data}

Our data set comprises quarterly time series over the 1993:Q2-2003:Q4 period. ${ }^{6}$ Figure 2 shows that during the first three quarters of 2002, the average unit value of ATM withdrawal per card (dashed line) records a sharp increase (from $€ 157$ to $€ 165$ ), but only after an equally sharp fall in $2001 .{ }^{7}$ Overall, the withdrawal per card after the changeover remains close to the values recorded in the previous five years. ${ }^{8}$ The same conclusion holds for the frequency of

\footnotetext{
${ }^{6}$ We refer to two sources. The flow of cash withdrawn from ATMs in Italy, the number of ATM cards, the number of POS and ATM terminals, and the interest rate on checking accounts are provided to the Bank of Italy by the banking system for supervisory reasons. Data on consumption of services and nondurable goods, and the related deflators, are released by the Italian national statistical office (ISTAT). All the series used in the paper refer to Italy.

${ }^{7}$ This swing is likely due to the need by currency holders to run down their cash inventories. As mentioned in the introduction, a massive drop in currency outstanding was recorded in 2001. As the cash changeover was largely anticipated by the public, it seems plausible that, in the final months of the year, currency holders avoided withdrawing cash and used their inventory for day-to-day purchases. After the changeover, the average use of ATM cash returned to normal.

${ }^{8}$ Such stationarity, in a period of moderate but positive inflation, might reflect the increasing use of cash substitutes; the regression analysis below supports this hypothesis.
} 
Vol. 3 No. 4 Did Prices Really Soar after the Euro Cash Changeover? 9

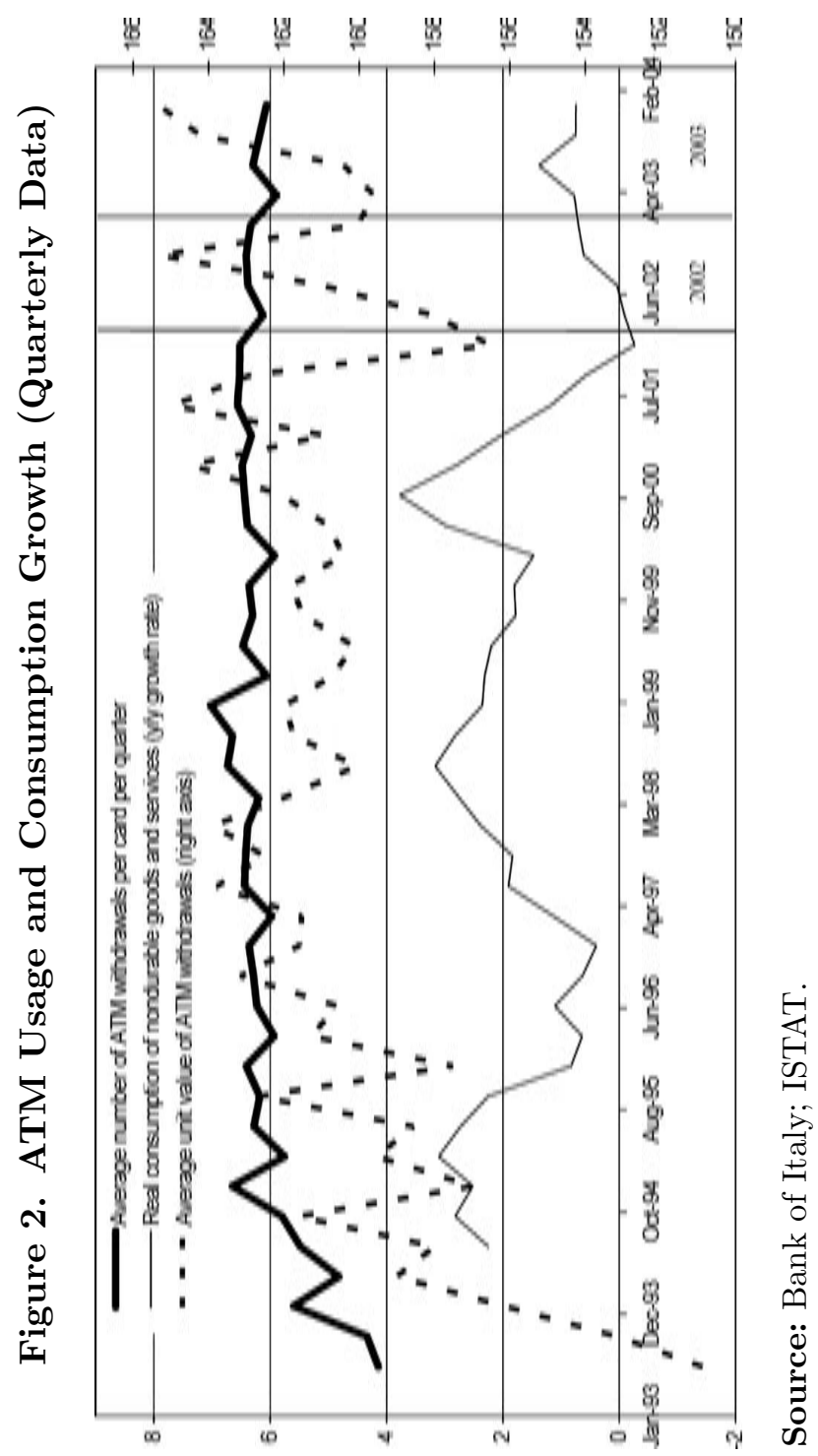


ATM usage (thick solid line), roughly constant at 6.3 withdrawals per card per quarter since 1995. Figure 2 also displays the behavior of households' real consumption of nondurable goods and services in the period (thin solid line). Growth begins to slow down in the second half of 2000, bottoming out in the fourth quarter of 2001.

At least prima facie, none of these time series display a behavior that might signal a sharp increase in the price level after the introduction of the euro bank notes and coins. However, this descriptive evidence can be potentially misleading, for at least two reasons. The first relates to our measure of consumption. Assume that inflation perceptions are correct and that the official nondurable goods deflator underestimates inflation in 2002-03; then, real-consumption growth in figure 2 would be correspondingly overestimated. Second, the descriptive evidence does not take into account several structural changes that have occurred over the last fifteen years-most notably, the diffusion of ATM and POS terminals, and the associated increase in aggregate cash withdrawals from ATMs and in the use of noncash payments via debit cards. Such developments typically follow low-frequency trends, so in our view it is unlikely that they may have obscured the effect of the hypothesized price jump on the demand for cash and alternative payment instruments in 2002-03. However, the model of section 2 suggests that they affect the demand for ATM withdrawals and should thus be taken into account. This is done in the next subsection.

\subsection{Inference from an Estimated Currency-Expenditure Equation}

A log-linear version of equation (3) yields

$$
c_{t}-p_{t}=\alpha+\beta d_{t}^{A T M}+\gamma d_{t}^{Q}+\delta\left(e_{t}-p_{t}\right)+\varepsilon r_{t}+\lambda n_{t}+\eta_{t},
$$

where $\eta_{t}$ is an error term with variance $\sigma_{\eta}^{2}$. We measure $c_{t}$ by the ( $\log$ ) nominal value of nationwide quarterly withdrawals from ATM terminals; we measure $n_{t}$ by the (log) number of outstanding ATM cards (at the end of the quarter). $r_{t}$ is the (log) interest rate on checking accounts. The diffusion of the ATM network, $d^{A T M}$, is proxied 
by the ratio between the number of ATM terminals nationwide and the number of ATM cards. Similarly, the diffusion of alternative payment instruments, $d^{Q}$, is measured by the ratio between the number of POS terminals and $n_{t}$. Finally, $e_{t}$ and $p_{t}$ are proxied by the $(\log )$ aggregate nominal consumption of services and nondurable goods, and by its deflator, respectively. ${ }^{9}$

Can equation (4) help us shed light on the issue at the core of this paper? For the answer to be positive, we must assume that all of the time series appearing in (4) are measured with no error until the fourth quarter of $2001 .^{10}$ This assumption seems reasonable, since until the end of 2001 there was no argument about data quality. It implies that the coefficients of (4) will not be affected by measurement problems if estimated over the pre-changeover period. Concerning the post-changeover period, we assume that all variables appearing in (4) are measured correctly, with the possible exception of the price level. Specifically, we allow for the possibility that $p_{t}$, the true (log) price level, may suffer from measurement error and deviate from its observed counterpart, $p_{t}^{o}$.

As anticipated in section 3 , a condition on the elasticity of cash withdrawals with respect to real consumption $(\delta)$ must also be satisfied. It is easy to see that if $\delta=1$, the price level cancels from both sides of (4), and the equation becomes uninformative on the price-level dynamics. Thus, an estimated $\delta \neq 1$ is necessary (and sufficient) to back out the price level after 2001 from (4).

We begin by estimating (4) using data until 2001:Q4. The results are reported in table 1 , column $1 .{ }^{11}$ The coefficients are in line with the model suggestions: the diffusion of noncash forms of payment reduces cash withdrawals, while the diffusion of ATM

\footnotetext{
${ }^{9}$ Based on equation (3), the population size, $N$, should also appear among the regressors. We omit it because it was roughly constant over the estimation period.

${ }^{10}$ More precisely, we are assuming that the measurement errors present in official statistics (e.g., the well-known price-index bias) are not affected by the changeover. Under our alternative hypothesis, we allow the euro changeover to bring about a source of measurement error in price measures additional to those that are ordinarily present.

${ }^{11}$ Three quarterly dummies (not shown) are included among the explanatory variables to account for seasonal effects.
} 


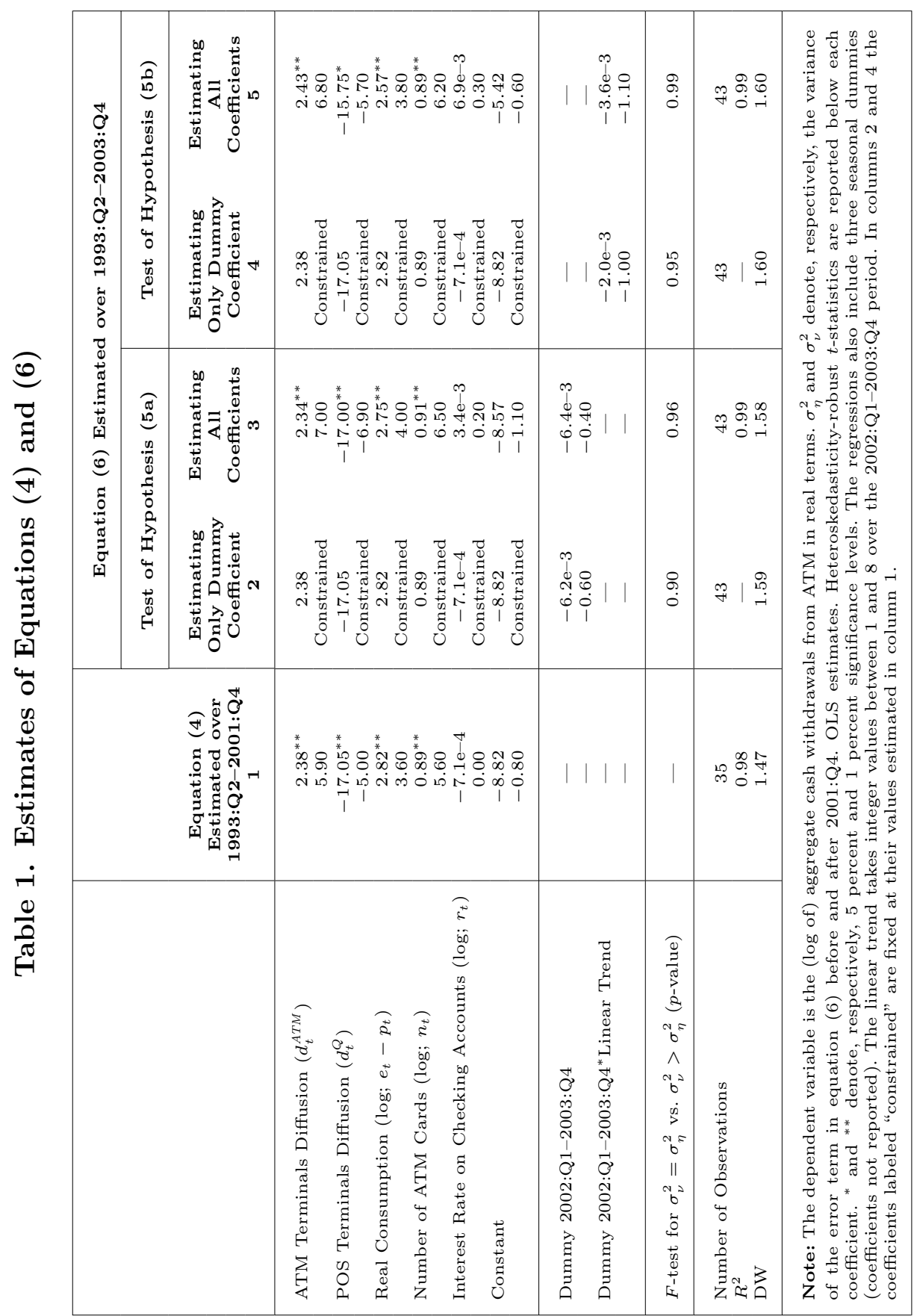


terminals increases them. The coefficient of the interest rate on checking accounts is negative but not significant. The coefficient of the number of ATM cards is 0.89 , not significantly different from 1 ( $t$-statistic of 0.7 ). The point estimate of the parameter $\delta$ is 2.82 , statistically greater than 1 at the 5 percent confidence level ( $t$-statistic of 2.2). Thus, the requirement spelled out above is satisfied; the functional form hypothesized in equation (2) finds support in the data. ${ }^{12}$

Altogether, while simple, equation (4) seems to capture some essential features of the demand for ATM withdrawals. Considering that it does not feature a lagged dependent variable on the righthand side (we experimented with specifications incorporating one, but the related coefficient turned out to be nonsignificant), it tracks the data quite well.

We can now test the null hypothesis - that after the changeover, $p_{t}=p_{t}^{o}$-against the alternative, $p_{t}>p_{t}^{o}$. Since $p_{t}$ is not observable after 2001:Q4, we consider two hypotheses about its behavior. The first is the following:

$$
\begin{array}{ll}
p_{t}=p_{t}^{o}, & t \leq 2001: \mathrm{Q} 4, \\
p_{t}=p_{t}^{o}+\Delta+\xi_{t}, & t \geq 2002: \mathrm{Q} 1,
\end{array}
$$

where $\Delta$ is a positive constant and $\xi_{t}$ is a white-noise term independent of $\eta_{t}$, with variance $\sigma_{\xi}^{2}$. The expressions in (5a) could be an appropriate description of a one-off increase in the true price level after the changeover. An alternative hypothesis is

$$
\begin{array}{ll}
p_{t}=p_{t}^{o}, & t \leq 2001: \mathrm{Q} 4, \\
p_{t}=p_{t}^{o}+g T+\xi_{t}, & t \geq 2002: \mathrm{Q} 1,
\end{array}
$$

where $g$ is a positive constant and $T$ is a linear trend $(T=1$ in 2002:Q1, $T=2$ in 2002:Q2,..). This formulation would entail a

\footnotetext{
${ }^{12}$ The microdata from the households survey run by the Bank of Italy also suggest that $\delta$ is greater than 1. Introducing time subscripts in (2), taking logs of both sides and differentiating, $\delta$ can be shown to equal the ratio between the growth rate of consumption expenditure for the average ATM cardholder and the corresponding growth rate for the average consumer. Between 1998 and 2004 this ratio averaged about 1.4, as consumption among cardholders consistently outgrew average per capita consumption at the nationwide level.
} 
widening gap between the observed (official) and the true price deflator, implying a permanent inflation bias. It would be unrealistic for large $T$ but could be appropriate over our sample period, which only covers eight quarters after the changeover. Substituting (5a) into (4) yields

$$
\begin{aligned}
c_{t}-p_{t}^{o}= & \alpha+\beta d_{t}^{A T M}+\gamma d_{t}^{Q}+\delta\left(e_{t}-p_{t}^{o}\right)+\varepsilon r_{t} \\
& +\lambda n_{t}+\eta_{t}, \quad t \leq 2001: \mathrm{Q} 4, \\
c_{t}-p_{t}^{o}= & \alpha+\theta_{0}+\beta d_{t}^{A T M}+\gamma d_{t}^{Q}+\delta\left(e_{t}-p_{t}^{o}\right)+\varepsilon r_{t} \\
& +\lambda n_{t}+\nu_{t}, \quad t \geq 2002: \mathrm{Q} 1,
\end{aligned}
$$

where $\theta_{0}=(1-\delta) \Delta$ and $\nu_{t}=\eta_{t}+(1-\delta) \xi_{t}$, with variance $\sigma_{\nu}^{2}=\sigma_{\eta}^{2}+(1-\delta)^{2} \sigma_{\xi}^{2}$. A way to test the null hypothesis of no distortion in the price level after the changeover against the alternative hypothesis (5a) would then entail estimating equation (6) over the entire sample period 1993:Q2-2003:Q4, introducing a dummy variable to allow the constant to change over the last two years, and checking for heteroskedasticity. However, it is easy to check that under the alternative hypothesis (5a), equation (6) is affected by a classic errors-in-variables problem; if $\sigma_{\xi}^{2}>0$, ordinary-least-squares (OLS) coefficients would be inconsistent and biased toward 0. To circumvent this difficulty, we restrict the parameters in (5a) to take the values estimated over the 1993:Q2-2001:Q4 period, and estimate only the coefficient of the 2002-03 dummy, $\theta_{0}$, which is an unbiased estimator of $(1-\delta) \Delta$. The results of this exercise are presented in column 2 of table 1 . The estimated $\theta_{0}$ has a value of -0.0062 ; using this figure and the estimated value for $\delta(2.82)$, it can be reckoned that the average inflation rate in 2002 was 0.3 percentage point higher than that computed using the official deflator. However, a one-tail $t$-test cannot reject the null that $\theta_{0}$ is 0 against the alternative that it is negative. Column 2 also reports the result of an $F$-test of the null hypothesis $\sigma_{\nu}^{2}=\sigma_{\eta}^{2}$ against the alternative $\sigma_{\nu}^{2}>\sigma_{\eta}^{2}$, which should hold based on (5a). Again, the null is not rejected.

As mentioned above, if (5a) were true and the errors-in-variables problem were serious after 2001:Q4, OLS coefficients should be biased toward 0 . Therefore, as a further check, we estimate all the parameters of (6) over the entire sample period. The estimated coefficients show that the parameters remain stable (see column 3). 
Next, we replicate the exercise for our second alternative hypothesis. Substituting (5b) into (4) yields an equation identical to (6), except that now $\theta_{0}=(1-\delta) g T$. Thus, beginning with 2002:Q1, a linear trend with coefficient $g(1-\delta)$ should enter the equation. Also, the error term should display the same form of heteroskedasticity as under hypothesis (5a). Specifications in columns 4 and 5 of table 1 show no evidence consistent with the hypothesis of an increase in the price level after the changeover. In both cases the coefficient of the 2002:Q1-2003:Q4 dummy interacted with the time trend is negative. A calculation based on the larger value, $-3.6 \mathrm{e}-3$, together with the estimated value of 2.82 for $\delta$, suggests that the average inflation rate in 2002 was 0.5 percentage point higher than that based on the official deflator. However, even in this case, the coefficient is not statistically different from 0 , and the null of homoskedasticity cannot be rejected. ${ }^{13}$

\subsection{Exploring the Power of the Statistical Test}

Our econometric procedure amounts to a $t$-test on the coefficient of a dummy in a linear regression. Therefore, the properties of our tests and their statistical power are well grounded in standard asymptotic and small-sample theory. It could be argued, however, that the precision of our estimates is insufficient to generate adequate power, e.g., because of the short sample period. To investigate this hypothesis, we perform a counterfactual exercise; we assume that beginning in 2002:Q1 the true price deflator is higher than the official one. Using (5a), we set $p_{t}^{o}=p_{t}-\Delta$ after the changeover. We then assign numeric values to $\Delta$ and reestimate the specifications shown in columns 2 and 3 of table 1 . If our tests have sufficient power, the coefficient of the 2002-03 dummy should become negative and significant for relatively small values of $\Delta$. We report the results of this exercise for values of $\Delta$ ranging between 0.005 and 0.1 , implying that in 2002 inflation was between

\footnotetext{
${ }^{13}$ While we focused on hypotheses $(5 \mathrm{a})$ and $(5 \mathrm{~b})$ in order to maximize the power of the test, we also tested hypothesis $p_{t}=p_{t}^{o}+\Delta+g T+\xi t, t \geq 2002$ : Q1, which nests (5a) and (5b). The estimated coefficients for the 2002-03 dummy and for the time-trend results were not statistically different from 0 (individually as well as jointly).
} 
0.5 and 10 percentage points higher than that recorded by official statistics.

Figure 3 plots the "true" $\Delta$, measured on the horizontal axis, against its estimated value, $\hat{\Delta}$, obtained as the ratio between the coefficient of the 2002-03 dummy and $(1-\delta)$. The curves obtained with the specifications shown in columns 2 and 3 of table 1 virtually overlap, so that they can hardly be distinguished in the figure. They are very close to the $45^{\circ}$ lines, indicating that the size of the distortion is captured quite well-in fact, it is systematically slightly overestimated. The figure also shows the precision of the estimates, measured by the $t$-statistic of the 2002:Q1-2003:Q4 dummy. Both specifications fail to detect the presence of a 0.5 -percentage-point distortion. However, the specification in column 2 manages to correctly signal as statistically significant (with a 5 percent confidence level) a value of $\Delta$ as little as 1 percent; in this case, the specification in column 3 yields a $p$-value of .09. Both specifications capture values of $\Delta$ greater than 1 percent, at least at the 5 percent confidence level.

\subsection{Robustness Check}

The above results were subjected to a number of robustness checks. First, we checked the stability of the specification reported in table 1, column 1. The exercises described in section 3.2 entail detecting a structural break in the equation after the fourth quarter of 2001. Thus, it is important that the coefficients in column 1 of table 1 be stable. An obvious candidate for a structural break is the beginning of the single euro-area monetary policy regime, in January 1999. Therefore, the five coefficients $\alpha$ through $\lambda$ of the specification in column 1 were allowed to change over the 1999:Q1-2001:Q4 period. The $F$-test of the null hypothesis that the changes in the coefficients are jointly equal to 0 yields $F_{(5,20)}=2.66$, which does not allow for rejection of the null of parameter stability at the 5 percent confidence level. However, since this value is close to significance, the tests in table 1 were replicated using the equation that allows for parameter change over the 1999:Q1-2001:Q4 period. The results were qualitatively analogous to those in table 1 and therefore are not reported. 
Vol. 3 No. 4 Did Prices Really Soar after the Euro Cash Changeover? 17

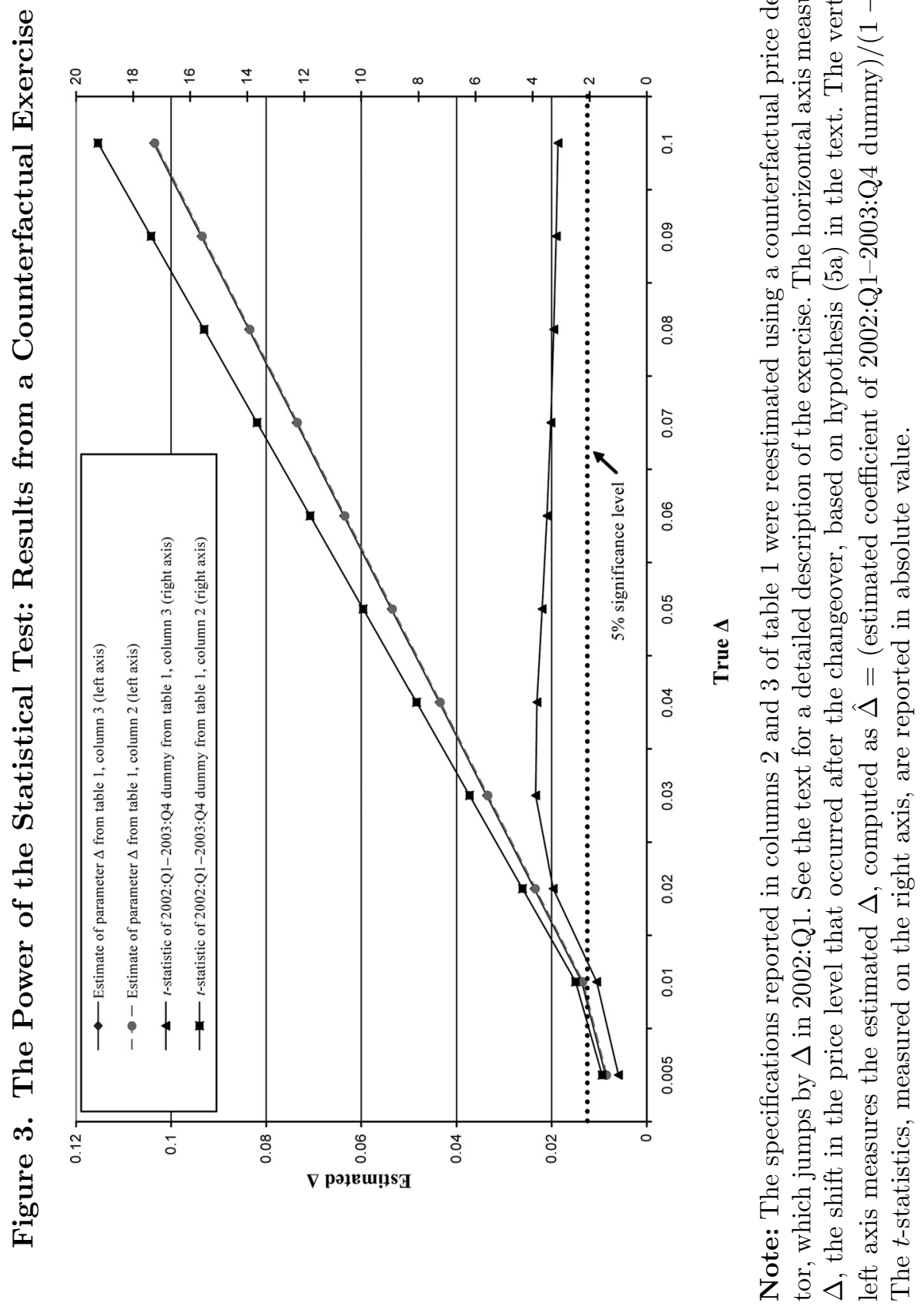


Second, the estimates of equation (4) reported in table 1 are subject to a potential endogeneity-bias problem, as some right-handside variables (e.g., expenditure) may be simultaneously determined with the dependent variable. Thus, we reestimated the specification in column 1 with two-stage least squares, instrumenting $d_{t}^{A T M}, d_{t}^{Q}$, $e_{t}-p_{t}$, and $n_{t}$ with their lagged values. The results (not reported) are virtually unchanged.

Third, the analysis in section 3.2 relies on the hypothesis that nominal expenditure $e_{t}$ is measured without error prior to and after the changeover. However, nominal components of consumption expenditure are computed using both value data (i.e., data measured in nominal terms) and data built from price and quantity indices. Possible mismeasurements in the prices of these components after 2001:Q4 will, in principle, bias $e_{t}$ as well. Since a detailed breakdown of the data on household consumption by construction method is not available, it is not possible to address this concern in a precise way (see ISTAT 2000). However, ISTAT does publish a breakdown of consumption expenditure used in section 3.2 into two categories: nondurable goods and services. The former is virtually entirely built from value data, and therefore it is not affected by possible mismeasurement in $p_{t}$ after the changeover. Thus, we rerun the regressions in table 1 , proxying $e_{t}$ with consumption of nondurable goods, i.e., excluding expenditure on services. ${ }^{14}$ Table 2 , in the appendix, reports the instrumental-variables estimates of this last specification. The elasticity of money demand to real consumption is now 2.3, slightly lower than in table 1 but still significantly different from 1 at the 5 percent confidence level. No appreciable changes in the other results emerge. Similar results were obtained with OLS.

Finally, we rerun our exercises using specifications featuring several alternative combinations of regressors: the number of ATM terminals, the number of POS terminals, the number of ATM cards

\footnotetext{
${ }^{14}$ Angelini, Ardizzi, and Lippi (2005) also use consumption of nondurables as a proxy for expenditure, in a specification featuring inflation and a time trend among the regressors. The results of the tests are analogous to those reported here.
} 
separately, and/or total households consumption (as opposed to consumption of nondurables and services). In this case as well, the main results of the analysis remain unchanged.

\section{Conclusions}

Did the euro cash changeover trigger a sudden, substantial increase in the price level in the euro area, largely undetected by the national statistical offices? This paper presented a simple indirect method to address this question for Italy. The basic idea underlying the testing strategy entails searching for the effects that the hypothesized large increase in the price level should have induced on the dynamics of payment instruments - notably, cash withdrawals from ATM terminals. A quarterly data set on aggregate ATM withdrawals and nominal consumption expenditures in Italy was used to test the hypothesis.

The estimation of a demand equation for ATM cash withdrawals, conducted along the lines suggested by a simple theoretical model, allows us to set up econometric tests of the null hypothesis (that after the currency changeover, in the first months of 2002, the official price index continued to measure the general price level correctly), against the alternative (that it underestimated it). The main result of the analysis is that none of the various tests performed provide evidence against the null. Specifically, our point estimates imply that the average inflation rate in 2002 was about one-half percentage point higher than that computed using the official deflator; however, this effect is not statistically significant.

To assess the possibility that failure to reject the null is due to lack of power, we perform a counterfactual exercise: we introduce an artificial increase in the deflator time series beginning in 2002 and rerun our tests. The equation accurately captures the magnitude of the inflation distortion, correctly signaling it as statistically significant as soon as it grows greater than or equal to 1 percent on an annual basis. We conclude that the determinants of the well-documented disconnect between official and perceived measures of inflation cannot be ascribed to a sizable mismeasurement by the national statistical offices of the euro-area countries. 


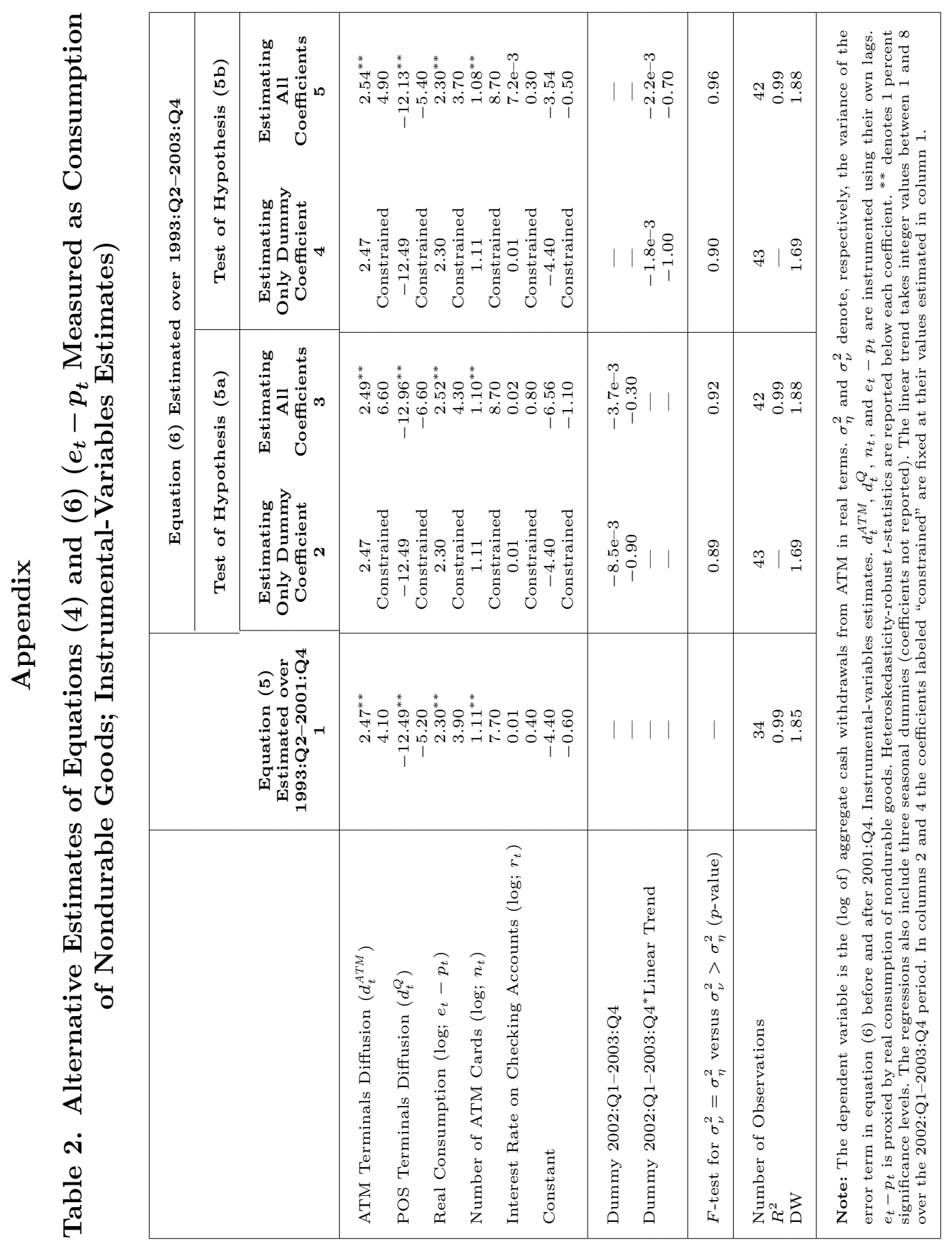


Vol. 3 No. 4 Did Prices Really Soar after the Euro Cash Changeover? 21

\section{References}

Angelini, P., G. Ardizzi, and F. Lippi. 2005. "Indicazioni indirette sulla dinamica dei prezzi: l'andamento del circolante e degli strumenti di pagamento in Italia e nell'area dell'euro." In L'euro e l'inflazione. Percezioni, fatti e analisi, ed. P. Del Giovane, F. Lippi, and R. Sabbatini. Bologna: Il Mulino.

Del Giovane, P., and R. Sabbatini. 2005. "The Introduction of the Euro and the Divergence between Officially Measured and Perceived Inflation: The Case of Italy." Mimeo. (Italian version published in L'euro e l'inflazione. Percezioni, fatti e analisi, ed. P. Del Giovane, F. Lippi, and R. Sabbatini. Bologna: Il Mulino). Deutsche Bundesbank. 2004. "The Euro and Prices Two Years On." Monthly Report 56 (1): 15-28.

Dziuda, W., and G. Mastrobuoni. 2005. "The Euro Changeover and Its Effects on Price Transparency and Inflation. Mission Euro, Mission Accomplished!" Mimeo, Princeton University.

Ehrmann, M. 2005. "Inattentive Consumers, Inflation Developments and Perceptions after the Euro Cash Changeover." Mimeo, European Central Bank.

European Central Bank. 2002a. "Impact of the Euro Cash Changeover on Currency in Circulation and M3." Annual Report 2001, 18-19.

- 2002b. "Recent Developments in Consumers' Inflation Perceptions." Monthly Bulletin (July): 18-19.

- 2003a. "Effects of the Introduction of the Euro Banknotes and Coins on Consumer Prices." Annual Report 2002, 40-42.

2003b. "Recent Developments in Euro Area Inflation Perceptions." Monthly Bulletin (October): 24-25.

Gaiotti, E., and F. Lippi. 2004. "Pricing Behavior and the Introduction of the Euro: Evidence from a Panel of Restaurants." Giornale degli Economisti 63 (3/4): 491-526.

Hobijn, B., F. Ravenna, and A. Tambalotti. 2006. "Menu Costs at Work: Restaurant Prices and the Introduction of the Euro." Quarterly Journal of Economics 121 (3): 1103-31.

ISTAT. 2000. Le nuove stime dei consumi finali delle famiglie. Metodi e Norme N. 7. Rome: ISTAT.

Lucas, R. E., Jr., and N. Stockey. 1987. "Money and Interest in a Cash-in-Advance Economy." Econometrica 55 (3): 491-513. 
Mastrobuoni, G. 2004. "The Effects of the Euro-Conversion on Prices and Price Perceptions." CEPS Working Paper No. 101. Traut-Mattausch, E., S. Schulz-Hardt, T. Greitemeyer, and D. Frey. 2004. "Expectancy Confirmation in Spite of Disconfirming Evidence: The Case of Price Increases Due to the Introduction of the Euro." European Journal of Social Psychology 34 (6): 739-60. 